\title{
Can Situational Action Theory Explain the Gender Gap in Adolescent Shoplifting? Results from Austria.
}

Helmut Hirtenlehner: Centre for Criminology, Johannes Kepler University Linz, Austria (helmut.hirtenlehner@jku.at)

Tel. 0043/732/2468-7446

Kyle Treiber: Institute of Criminology, University of Cambridge, UK

(kht25@cam.ac.uk)

Tel. 0044/1223-762947

Word count: 11,352

Correspondence to:

Helmut Hirtenlehner

Johannes Kepler University Linz

Centre for Criminology

Altenberger Strasse 69

A-4040 Linz

Austria

helmut.hirtenlehner@jku.at 


\title{
Can Situational Action Theory Explain the Gender Gap in Adolescent Shoplifting? Results from Austria.
}

\begin{abstract}
Although shoplifting is one of the crimes with the smallest gender gap among all offense types, most studies still conclude that males steal from shops more frequently than females. The roots of the gendered distribution of shoplifting have not yet been satisfactorily explained. This work investigates whether Situational Action Theory can account for males' greater involvement in shoplifting compared to females and if the propensity-exposure interaction that is at the heart of the theory applies to both genders. Results from a large-scale student survey conducted in Austria suggest that Situational Action Theory generalizes to both genders and that it is well suited to explain why males are more likely to shoplift than females.
\end{abstract}

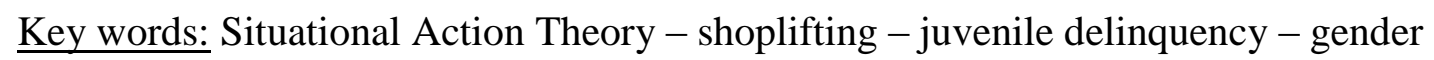




\section{Can Situational Action Theory Explain the Gender Gap in Adolescent Shoplifting? Results from Austria.}

\section{KEY RESEARCH QUESTIONS}

One of the few robust findings of decades of criminological research is that crime is committed more frequently by males than by females, and that this gender gap increases with the seriousness of the offense (Junger-Tas et al., 2004; Moffitt et al., 2001; Steffensmeier \& Allan, 1996) ${ }^{1}$. Compared to more serious property or violent crimes, higher proportions of female offenders are associated with milder forms of property crime, such as shoplifting (Bamfield, 2012; Steffensmeier \& Allan, 1996). Indeed, shoplifting is often seen as a "pink collar crime", an offense committed predominantly by females. This is consistent with the stereotype that shopping is a female pursuit (or leisure activity) in many segments of society. However, contrary to this assumption most studies report higher rates of shoplifting among males than among females (Bamfield, 2012; Blanco et al., 2008; Farrington, 1999; Klemke, 1992; Krasnovsky \& Lane, 1998; Piquero et al., 2005; Tonglet, 2002; Wittenberg, 2009). Nonetheless, some evidence suggests that this gender gap may be shrinking: several recent studies have reported nearly equivalent shoplifting rates for males and females (Enzmann, 2010; Killias et al., 2010; Marshall \& He, 2010) while others even indicate that, especially in younger cohorts, rates amongst females may be beginning to surpass those amongst males (Wikström et al., 2012; Wikström \& Butterworth, 2006).

Along with violence and vandalism, shoplifting is one of the most common forms of adolescent offending in contemporary European societies (Junger-Tas, 2012; Stummvoll et al., 2010; Wikström et al., 2012). It is therefore astonishing that it remains so vastly underresearched (Wittenberg, 2009). This, coupled with the fact that shoplifting appears to be on the rise in recent years, renders it an important topic for criminological inquiry. Although individual acts cause little harm ${ }^{2}$ (Bamfield, 2012), they are so prevalent that overall shoplifting generates considerable economic harm. According to the Global Retail Theft Barometer (The Smart Cube, 2015), during 2014/15 shoplifting cost the global retail market approximately $\$ 47$ billion ( $0.5 \%$ of total sales), and the European market approximately $\$ 17$

\footnotetext{
${ }^{1}$ We use the concept of "gender" rather than "sex", because in this paper we write in a sociological tradition and do not focus on biological differences between males and females.

${ }^{2}$ For example, in Germany $50 \%$ of all incidents of shoplifting reported to the police in 2011 involved stolen goods worth less than $€ 15$ (Bundeskriminalamt, 2012).
} 
billion ( $0.4 \%$ of total sales). Just prior to this study - during 2010/11 - Austrian retailers suffered losses from shoplifting amounting to $\$ 310$ million (0.6\% of total sales) (CRR, 2011). This rose to $\$ 539$ million (or $0.7 \%$ of total sales) by 2014/15 (The Smart Cube, 2015).

Shoplifting is of course not just a European issue. The U.S., for example, experienced a similar cost of shoplifting to the European market: \$ 13 billion in 2014/15 (0.5\% of total sales) (The Smart Cube, 2015). And across 30 different countries, the International SelfReport Delinquency Study (ISRD-2; 2005-2007) showed that shoplifting was by far the most common self-reported property crime among 12-15 year-olds, with $17.3 \%$ of youths reporting having shoplifted at least once in their previous life (Marshall, 2013).

The lack of empirical attention to shoplifting, despite it being one of the most common crimes and associated with such large financial costs (Hindelang et al., 1981; Klemke, 1992), means that the overrepresentation of females amongst shoplifters compared to other types of offenders has received little empirical scrutiny (for an exception see Hirtenlehner et al., 2014, or Piquero et al., 2005). It has also been neglected in theoretical reflections, and therefore remains largely unexplained, consistent with more general criminological shortcomings in explaining the gender dynamics of crime.

Scholars studying the relationship between gender and crime typically draw on the major criminological perspectives (e.g., control theories, general strain theory, differential association and social learning theories, routine activity theory, etc.; see, for example, LaGrange \& Silverman, 1999; Burton et al., 1998; Alarid et al., 2000; Broidy \& Agnew, 1997; Piquero \& Sealock, 2004) ${ }^{3}$. Most of these theories have been developed with male offenders in mind, but assume that the causes of offending are the same for males and females. Available research generally supports this assumption, indicating that traditional theories apply equally well to male and female offending and the same factors predict male and female crime involvement (Agnew, 2009; Hubbard \& Pratt, 2002; Moffitt et al., 2001; Wong et al., 2010). However, some studies report these factors have slightly different effects on males and females. For instance, some family and peer variables appear to be more closely related to female offending, whereas some individual and school variables appear more closely associated with male offending (Agnew, 2009; Steketee et al., 2013; Svensson et al., 2016; Wong et al., 2010). This is not surprising given the complexity and interactive nature of

\footnotetext{
${ }^{3}$ Theories explicitly focusing on the gendered nature of criminal activity are rare (e.g., Hagan, 1989; HayslettMcCall \& Bernard, 2002; Messerschmidt, 1993; Steffensmeier \& Allan, 1996).
} 
crime causation and the fact that many relevant factors are not evenly distributed between males and females.

For a theory to be gender adequate, it must not only explain crime equally well for males and females (the generalizability problem), but also why males commit more crime than females (the gender ratio problem) (Daly \& Chesney-Lind, 1988). Research suggests that traditional criminological theories can explain significant portions, but not all of the gender gap in offending behavior (Agnew, 2009). Controlling for key factors (e.g., self-control, social bonds, peer delinquency, supervision) usually reduces the gender effect considerably, but seldom to zero or insignificance (Junger-Tas et al., 2004; LaGrange \& Silverman, 1999; Mears et al., 1998; Piquero et al., 2005). In most studies, a non-negligible part of the gender effect remains unexplained (Weerman et al., 2015, p.4). Hence none of these factors, or related theories, has proven perfectly effective in accounting for the gender divide.

It may be argued that the inability of scholars to fully explain both the similarities and differences in male and female offending reflects persistent shortcomings in traditional criminological theories. One significant shortcoming is a lack of integration of individual and environmental levels of explanation (Wikström, 2006). A growing body of research from across the behavioral sciences emphasizes the importance of person-environment interactions for understanding development and behavior (Belsky \& Pluess, 2009; Blakemore \& Choudhury, 2006; Ferguson-Smith, 2011; Lipina \& Posner, 2012; Rutter, 2012; Simons et al., 2014; Wikström et al., 2012). Males and females differ on both fronts, i.e., not only socioculturally (in terms of their environmental influences) but also biopsychologically (in terms of their personal characteristics and experiences). Gender is a proxy for both unmeasured biological characteristics and unobserved cultural processes. Ignoring either may leave criminological explanations of gender differences in offending shortsighted (Jessor, 1992; Thijs et al., 2015).

Another significant deficiency of major criminological theories is the lack of sufficiently detailed mechanisms by which key factors cause people to commit acts of crime (Wikström, 2006; Wikström \& Treiber, 2016). Without a clear understanding of what moves people to offend, it will remain impossible to explain why males and females experience different imperatives.

Situational action theory (SAT; Wikström, 2004, 2006, 2010, 2012, 2014) proposes to address these shortcomings by integrating person-oriented and environment-oriented explanations of crime in a framework that details the mechanism through which people and environments 
interact situationally (at the point of action) to cause crime. According to SAT, crime happens when a person comes to see and choose crime as an action alternative. This perception-choice process is shaped by the interaction between a person's crime propensity and his or her criminogenic exposure. So the centerpiece of the theory is the interaction between people and their social surroundings, which triggers a perception-choice process that directly governs action.

According to SAT, behavior is always the result of a perception-choice process comprising two stages: the perception of behavioral alternatives in response to a particular motivation and the choice of which alternative to pursue. SAT argues that perception processes are more important than choice processes for explaining why crime happens. This is the case because perception processes determine which action alternatives a person considers in relation to a certain motivation. SAT suggests that rules about right and wrong actions play a significant role in perception. People differ in what actions they think are right or wrong and how strongly they feel about doing the right thing (their personal morality). Places differ in what actions are defined (e.g. by law) as right or wrong and how strongly they indicate and enforce these rules (their moral context). Together, people's personal rules and the rules of the setting they take part in determine whether or not they see crime as an action alternative.

The perception process (guided by personal morality and the moral context) not only determines which action alternatives are considered, but also shapes the process of choice. If only one alternative is considered, the choice process is automatic or habitual. Automatic or habitual choice is often neglected in standard models of decision-making, but there is growing evidence of the importance of automatic or habitual behaviors in human action (Treiber, in press). Most decision-making models focus on choices between competing alternatives. SAT recognizes that these kinds of choices are also prominent in criminal decision-making, but it does not adopt the common assumption that people evaluate their options rationally, based primarily on perceived costs and benefits (typically to themselves). Rather, SAT argues that people assess their options based on preferences, which may be associated with potential costs and benefits, but are constrained by their moral values.

Furthermore, SAT points out that controls (i.e. self-control and deterrence) are only relevant when people deliberate - more precisely: when they choose between competing alternatives including crime. In the case of habitual choices, people either do not recognize the need to exercise self-control (they see nothing wrong with the perceived action) or are unaffected by deterrents in the setting (they are not made aware that the perceived action is wrong). SAT 
defines self-control as an individual's ability to align his or her behavior with his or her moral values when faced with external pressures which tempt or provoke him or her to do otherwise (Wikström, 2004, p. 16 f.) ${ }^{4}$. Self-control therefore comes into play when a setting's moral context encourages a person to see crime as an option in opposition to his or her personal morality. SAT defines deterrence as a setting's ability to align a person's behavior with the rules of the setting when his or her personal desires, commitments or sensitivities lead him or her to consider doing otherwise (Wikström, 2008). Deterrence therefore comes into play when a person's morality encourages him or her to see crime as an option in opposition to the rules of the setting. Hence, controls are only conditionally relevant.

A person's overall tendency to see and choose crime as an action alternative is referred to as his or her crime propensity. It is determined by his or her personal morality and ability to exercise self-control. A setting's overall tendency to lead people to see and choose crime as an action alternative is referred to as its criminogeneity, and the nature and extent of time that people spend in criminogenic settings is described as their criminogenic exposure. Criminogenic settings include settings in which other actors (e.g. criminal peers) facilitate the perception of crime as an action alternative because they convey moral norms which are inconsistent with the law (e.g. encourage shoplifting), as well as settings that foster choosing crime because they present low detection and sanction risks (e.g. lack monitoring). At its core, SAT posits that the likelihood that a person will commit offences depends on the interplay between his or her crime propensity and his or her criminogenic exposure. The theory argues that the impact of exposure to criminogenic settings depends on an individual's propensity for crime: those with higher crime propensity will be situationally vulnerable - exposure to crime-conducive settings may activate their tendency to see and choose crime as an option and thereby have a significant effect on their behavior - while those with a lower crime propensity are situationally resistant and do not see crime as an option even when exposed to crime-conducive settings 5 .

An application of SAT to gender differences in crime involvement would suggest males' higher levels of offending could be explained by their having higher crime propensities (i.e., greater susceptibility to criminogenic environments), greater exposure to criminogenic

\footnotetext{
${ }^{4}$ SAT's conceptualization of self-control is similar to that of Hay and Meldrum (2016, p. 7) who define trait selfcontrol as capability "of overriding immediate impulses to replace them with responses that adhere to higherorder standards that typically follow from values, social commitments, and interests in long-term well-being".

${ }^{5}$ Some of the core insights of SAT have already been anticipated in Klemke's (1992, p. 112) "Sociology of Shoplifting": "When a vulnerable individual is exposed to social influences (...) that make shoplifting attractive, there is a greater likelihood that shoplifting will be (...) chosen".
} 
environments (i.e., more frequent activation of crime propensities), or both, leading them to see and choose crime as an option more frequently, albeit through the same causal process. Thus SAT would not suggest that male and female offending requires different explanations. According to Bunge (2004), to explain means to identify the mechanism or process that brings about a particular effect. SAT clearly maintains that the perception-choice process triggered by the interaction between crime propensity and setting criminogeneity is the same for males and females. This does not, however, preclude the fact that males and females may come to acquire different crime propensities and experience different criminogenic exposure, owing to a variety of developmental and social factors.

Research testing various theoretical perspectives has generally supported the contention that males exhibit more personal characteristics and experience more environmental influences conducive to crime involvement than females, while evidence that those factors exert different influences on males and females remains weak (Agnew, 2009; Moffit et al., 2001; Weerman et al., 2015). With one exception (Weerman et al., 2015), SAT has not been used to study the relationship between gender and crime, although it may provide further insights. The present article therefore seeks to further explore SAT's potential to account for the gender ratio and the generalizability problem which previous criminological theories and inquiries have been unable to adequately explain. It draws on the example of adolescent shoplifting, using a largescale student survey from Austria as empirical foundation.

The first research question is whether the gender gradient of adolescent shoplifting can be explained by propositions derived from SAT. This study examines to what extent crime propensity, criminogenic exposure, and their interaction, which are key to SAT, can account for males' greater involvement in shoplifting than females'. The employed data also enables us to investigate whether, with regard to shoplifting, a high crime propensity converges more often with elevated criminogenic exposure among males than females.

The second research question addresses the generality of the theory. It has been argued (Moffitt et al. 2001) that males' disproportionate crime involvement can result from their more frequent exposure to key influences (the differential exposure hypothesis), as well as from their greater susceptibility to the deleterious impact of those influences (the vulnerability hypothesis). SAT would contend that due to the interactive nature of the causes of crime both may be true, but that the causes of crime, and the causal process linking them to crime, will be the same for males and females. Therefore we will investigate whether the crucial explanatory factors - and especially their interplay - apply equally to both male and female shoplifting. 
Thus, we investigate whether SAT is valid for both males and females, and therewith adolescent shoplifting generally.

\section{REVIEW OF EXISTING RESEARCH ON SITUATIONAL ACTION THEORY, GENDER AND CRIME}

A cause can be defined as "an entity (event, condition) that ... has the power to initiate a causal process that produces a particular effect" (Wikström, 2012, p. 57). According to SAT, the causal process that brings about criminal action is the perception-choice process, through which a person comes to see and choose crime as an action alternative, which is triggered when an individual with a certain criminal propensity encounters a setting with a certain criminogeneity. Thus, a person's crime propensity and criminogenic exposure are the interactive causes of his or her criminal conduct.

Gender is not regarded as a genuine cause of crime in SAT, not even as one of the causes of the causes. The state of being male or female (socially or biologically) is not causally effective; it does not move an individual to commit an act of crime. Instead, gender is described as an attribute or marker that may be related to characteristics or experiences relevant in crime causation, such as crime propensity and criminogenic exposure (Wikström, 2007, 2012). Since gender is associated with the causes (and the causes of the causes) of behavior, it is predictive of criminal conduct without being a cause itself.

Nevertheless, an alternative approach may be to consider gender as one among many causes of the causes $\left(\right.$ Gangl, 2010) ${ }^{6}$. Gender certainly has the potential to shape processes and relationships that influence both an individual's crime propensity and his or her criminogenic exposure. For example, gender can affect processes of social and self selection that shape people's activity fields. This has consequences for the kind and extent of moral education and cognitive nurturing they receive, and therewith also for their development of different crime propensities. Gendered selection processes can result in differential exposure to contexts in which these propensities may be expressed. Biological characteristics can have an impact on how males and females respond to different experiences, and the cumulative effects of these experiences can lead to differences in desires, commitments, sensitivities and preferences. So, mediated by a variety of biological, developmental and social factors and processes (e.g.

\footnotetext{
${ }^{6}$ Gangl (2010, p. 38 f.) makes it very clear that nonmanipulable factors such as gender and race have causal significance because they place individuals into socialization patterns and opportunity structures.
} 
genetic endowment, socialization, controls, routine activities, social networks), gender may be part of a complex causal chain underlying individual behavior and therewith gender differences in crime involvement.

But despite gender differentials in the distribution of crime propensity and criminogenic exposure, SAT would argue that females with high crime propensity and criminogenic exposure will be just as likely to offend as males with similar levels, and that males with low crime propensity and criminogenic exposure would be just as likely to not offend as females with similar levels; it is their propensity and exposure, not their gender, that determines, and can explain, their crime involvement.

Research on the gendered distribution of the factors affecting crime propensity and criminogenic exposure supports these assertions. Numerous studies have found that females, compared with males, have stronger personal morals (Mears et al., 1998; Piquero et al., 2005; Svensson, 2004; Weerman \& Hoeve, 2012) and higher levels of self-control (Gavray et al., 2013; Hirtenlehner \& Blackwell, 2015; LaGrange \& Silverman, 1999; Marshall \& Enzmann, 2012). Females also tend to perceive greater risks of being detected and punished (Grasmick et al., 1993a; Hagan, 1989; Hirtenlehner et al., 2014; Piquero et al., 2005), acquire fewer criminal friends (Mears et al., 1998; Moffitt et al., 2001; Piquero et al., 2005; Weerman \& Hoeve, 2012), and spend less time hanging out with their peers (Bottcher, 2001; Mears et al., 1998; Weerman \& Hoeve, 2012). The former attest to differences in their crime propensities, the latter to differences in their criminogenic exposure.

To date, only one study has directly analyzed these gender differences and their relation to crime within the SAT framework. Using longitudinal data from adolescents attending schools in The Hague (Netherlands), Weerman and colleagues (2015) investigated to what extent SAT's key components of crime propensity and criminogenic exposure are equally related to crime involvement among males and females and can explain the gender ratio in crime involvement.

Results showed that the effect of gender on delinquency is substantially reduced when core indicators of propensity (morality, self-control) and exposure (unsupervised peer activities, association with rule-breaking peers) are entered as control variables into Tobit regression models. The fact that a small significant gender effect remains may be due to a failure to include the propensity-exposure interaction into the explanatory models, which means that this study can only be regarded as a partial test of SAT's potential to address the gender ratio 
problem. Findings also demonstrated that the effects of the employed predictor variables do not differ between males and females, indicating that SAT is applicable to both genders.

In a series of studies, Pauwels (2012, 2015; Schils \& Pauwels, 2014) also tested SAT's applicability to the generalizability problem. Drawing on data from adolescents in Belgium, Pauwels and colleagues investigated the interplay between crime propensity and criminogenic exposure within subgroups of males and females from native and migrant backgrounds. The common finding from these works was that SAT's propensity-exposure interaction emerges within all subgroups, indicating that the postulated interaction dynamics are invariant across gender (and ethnicity).

These studies provide support for SAT's ability to explain offending by males and females (the generalizability problem) and partial support for its ability to explain differences in crime involvement between males and females (the gender ratio problem). In this study we will explore whether this holds true in the case of adolescent shoplifting and if a full test of SAT, which includes the propensity-exposure interaction, can fully account for gender differences in theft from shops.

\section{METHODS}

\section{Data}

The data comes from the Austrian Adolescent Shoplifting Survey, a school-administered online survey of 2,911 students in the seventh and eighth grade, conducted in two Austrian provinces (Upper and Lower Austria) in 2011. The majority of participants were 13 and 14 years old. Males and females are equally represented in the sample (see Table 1).

Sampling followed a multi-stage procedure. At stage one, a random sample of 50 schools from Upper Austria and 42 schools from Lower Austria was selected. ${ }^{7}$ This sample was disproportionally stratified by school type. At stage two, a random selection of one seventh and one eighth grade class per school was taken. At stage three, all students in the selected classes were included. This yielded a final sample size of 2,911 students $(86 \%$ of the original sample due to absences and refusals).

\footnotetext{
${ }^{7}$ To achieve this net sample of 92 schools, 115 schools registered by the provincial supervisory school authorities were contacted ( $80 \%$ participation rate).
} 
Design weights are applied to this dataset to adjust for unequal selection probabilities resulting from the disproportionate sampling plan. Prior to statistical analysis, this design weighting was complemented with a post stratification of the data ${ }^{8}$. The latter was based simultaneously on province, grade and gender. Hence, the sample is fully representative of the population with respect to these characteristics. The composition of the sample is reported in Table 1.

The survey was conducted online during class time, when each class was led to the schools' computer room to complete the survey under the instruction of trained interviewers. Teachers were present to ensure discipline, but the interviewers made certain that the teachers could not see the answers provided by the students.

- Insert Table 1 about here -

\section{Measurement}

Shoplifting: Shoplifting frequency was measured by the question "How many times have you taken something from a shop without paying for it in the last 12 months?" In total, 5.1\% of the respondents reported having shoplifted at least once during the year before the survey; a proportion close to the 1-year-prevalence rate of $6 \%$ reported by Austrian participants of the ISRD-2 study (Stummvoll et al., 2010) ${ }^{9}$.

Propensity: In line with SAT's contention that a person's morality and his or her ability to exercise self-control are the key factors that shape an individual's crime propensity, Z-scores of sub-scales for these concepts were summed to create a composite measure for a respondent's propensity to shoplift.

To assess shoplifting-relevant morality, an index variable was generated that combines three items tapping into the perceived wrongfulness of theft from shops, and feelings of guilt and shame about shoplifting. A sum score merging moral beliefs and moral emotions was constructed by adding up the three Z-standardized item values (Cronbach's $\alpha=.71$ ).

The ability to exercise self-control was measured with an abridged version of the self-control scale utilized by Wikström and colleagues (2012), which builds on the inventory developed by Grasmick et al. (1993b). The six employed items tap particularly, but not exclusively, into

\footnotetext{
${ }^{8}$ The results reported in this paper remain stable when the unweighted data is used.

${ }^{9}$ With sampling being based on grades 7 to 9 , the Austrian ISRD-2 study draws on a nearly equivalent age group.
} 
the impulsivity and risk-taking dimensions of the construct that are most consistent with SAT's conceptualization of self-control and which have been shown to be most predictive of criminal behavior (Arneklev et al., 1993; Vazsonyi et al., 2001; Wikstrom \& Treiber, 2007). Responses on a four-category scale were summed to form a total score (Cronbach's $\alpha=.63$ ).

Morality and the ability to exercise self-control are correlated with $r=.35(p \leq .001)$.

Exposure: In accordance with SAT's idea that people's exposure to criminogenic settings is determined by the moral context of the environment to which they are directly exposed and the deterrent quality of the settings in which they take part, Z-scores of sub-scales for these constructs were added up to generate a composite measure of a respondent's shopliftingrelated exposure.

The moral context of the settings our respondents encounter was determined by their level of exposure to criminal peers. Underlying this is the assumption that adolescents who associate on a regular basis with friends who demonstrate and advocate theft from shops are more frequently faced with shoplifting-permissive settings. It has been shown that adolescents spend much time in the company of friends of the same age (Warr, 2002; Wikström et al., 2012). They also spend more time in shops with their friends. Research has established that adolescent shoplifting is typically a group phenomenon, with co-offending being the rule, not the exception (Farrington, 1999; Wikström et al., 2012). So the more time young people spend in the presence of peers who hold favorable definitions of shoplifting, the more often they will be confronted with moral settings in which the perception and choice of shoplifting is encouraged. In brief, because friends, whether mentally or physically present, can signal and enforce certain moral norms, close bonds to peers who encourage criminal conduct may serve as an indication of increased exposure to crime-conducive moral contexts ${ }^{10}$.

Perceived moral support of shoplifting among friends was assessed by two items. Respondents' perceptions about both their friend's moral beliefs about shoplifting and the proportion of friends perceived to be involved in shoplifting recently were used as an indicator of the moral context of shoplifting-relevant settings. The two highly intercorrelated items $(r=.55)$ were summed, and coded so that higher values reflect more criminogenic peers, providing a proxy for greater exposure to weak moral contexts.

\footnotetext{
${ }^{10}$ Although many characteristics of a setting can contribute to its moral context, one key element is certainly the type of people present in the setting. "[Y] oung people's exposure to criminogenic settings is dependent on the places they frequent and with whom they... frequent them" (Wikström, 2009, p. 257). Although a setting's moral context is also shaped by other people (e.g., sales staff or adult customers), in the case of young people peers can be regarded as particularly influential (Warr, 2002).
} 
The deterrent character of shoplifting-relevant settings was operationalized as the product of the perceived certainty of detection and the expected sanctioning severity. Both items $(r=.22$; $p=.000)$ were multiplied and coded so that a high value indicates weak deterrence.

Involvement with shoplifting-prone peers and perceived deterrence are highly correlated; $r=.81$ ( $p \leq .001)$. Respondents who have more crime involved friends perceive less deterrence.

Gender: Females were coded 0, males were coded 1.

Table 2 provides descriptive statistics and correlations for all measures employed in the ensuing analyses.

- Insert Table 2 about here -

\section{Analytic plan}

Crime frequency measures are normally analyzed with negative binomial regression models (Hilbe 2011). These models take account of the skewed and discrete nature of an overdispersed incidence variable. SAT's emphasis on interactive relationships, however, requires a rejection of this procedure. Recent methodological studies (Ai \& Norton, 2003; Berry et al., 2010; Bowen, 2012, Karaca-Mandic et al., 2012) suggest that the established practice of testing interaction effects by adding product terms to the model equations does not perform well in non-linear models such as logistic or negative binomial regression analyses. Nonlinear models confound two types of interaction: a model-inherent coefficient variation resulting from the specific form of the employed link function (i.e., from the multiplicative nature of the model) and the interaction that is captured by a product term. Both types of interaction can cancel each other out, which implies that a significant product term is neither necessary nor sufficient for claiming interaction (Berry et al., 2010; Bowen, 2012).

In view of these problems, this work relies on linear regression analyses to examine the hypothesized interdependencies (Aiken \& West, 1991). The extremely skewed distribution of the shoplifting frequency variable certainly violates key assumptions of the linear regression model (multivariate normal distribution and homoscedasticity), but this is partially defused by log-transforming it. Logarithmic transformations of the dependent variable help to alleviate skewness and heteroscedasticity, but they unfortunately also reduce the power to establish interactions (Russell \& Dean, 2000). Therefore, and given that non-experimental survey research is generally riddled with difficulties in detecting interaction effects (McClelland \& 
Judd, 1993), any findings supporting the existence of interaction relationships while employing log-transformed response variables are particularly impressive.

All regression models were fit using Stata 14 (StataCorp, 2015). Predictor variables were zstandardized before computing the multiplicative interaction terms (Aiken \& West, 1991). Due to the non-normal distribution of the dependent variable - the skewness of logged crime frequency amounts to 6.33 - clustered robust standard errors were employed (Hannon \& Knapp, 2003). Robust standard errors provide wider confidence intervals, which correct for the heteroscedasticity of the residuals. The clustering takes the nesting of students in classes into account, which would otherwise imply a serious underestimation of the standard errors and an overestimation of the significance levels.

Additionally, the propensity-exposure interplay is graphically depicted in interaction diagrams. For these charts, the predictor variables were dichotomized at the median for illustrative purposes.

\section{RESULTS}

Gender ratio problem

The gender gradients of the included concepts conform to expectations. The well-known gender gap in delinquent behavior can also be found for adolescent shoplifting: $7.3 \%$ of the males report having committed at least one act of shoplifting in the last 12 months, compared to only $2.8 \%$ of the females $(p=.000)$. The average annual shoplifting frequency of males significantly exceeds that of females.

- Insert Table 3 about here -

As regards the explanatory factors, males exhibit both a higher level of criminal propensity and more exposure to criminogenic settings. This observation is consistent with the differential exposure hypothesis, but does not provide a full test of SAT's argument. SAT actually implies that males are more involved in crime than females because for them high crime propensity and strong criminogenic exposure converge more frequently. In line with this proposition, data show that among males a high propensity for shoplifting combines with an elevated shoplifting-conducive exposure nearly twice as often as among females (42.2\% 
vs. $22.9 \% ; p=.000$ ). The risk of facing this particularly criminogenic propensity-exposure combination is 1.84 times higher for males compared to females.

The significance of the gender difference in shoplifting activity is also confirmed by linear regression models predicting log-transformed shoplifting frequency. Model 1 in Table 4 demonstrates that males are more likely to shoplift than females. This gender effect vanishes as soon as explanatory variables derived from SAT are introduced into the analyses. Controlling for the main effects of crime propensity and criminogenic exposure suffices to explain away the gender gradient (Model 2 in Table 4). Additionally including the propensity-exposure interaction - the multiplicative term capturing the dependency of the environmental effect on an individual's propensity to shoplift - does not change the picture (Model 3 in Table 4). In total the unstandardized gender coefficient drops from 0.0611 to 0.0125 , which equals a reduction by $80 \%$. These findings suggest that SAT clearly has the potential to account for the gender divide in juvenile shoplifting.

- Insert Table 4 about here -

The last model can also be read as a partial test of SAT's power to explain adolescent shoplifting, controlling for gender. It becomes apparent that propensity and exposure are significantly related to offending, as is their interplay. The postulated propensity-exposure interaction is accorded significance: criminogenic exposure increases shoplifting particularly when the propensity to shoplift is high. Exposure seems to be somewhat more influential than propensity, but in essence it is their interaction that counts. The product term exhibits the highest $\mathrm{T}$-value, indicating that the interaction contributes most to the explanation of the response variable. This conclusion is also supported by the fact that including the multiplicative term raises the proportion of explained variance from $14 \%$ to $24 \%$. In all, the observation that the impact of exposure to crime-conducive settings depends on the level of crime propensity - with criminogenic exposure predicting shoplifting activity especially among individuals with high crime propensity - provides firm support for a core proposition of $\mathrm{SAT}^{11}$.

\section{Generalizability problem}

To assess whether the postulated effect dynamics are invariant across gender, separate regression analyses were conducted for females and males. For both female and male

\footnotetext{
${ }^{11}$ Regression models utilizing untransformed shoplifting frequency as the response variable yield substantively identical results.
} 
respondents, log-transformed shoplifting frequency was regressed on crime propensity, criminogenic exposure and their interaction (Model 2 in Table 5). The results reveal considerable homogeneity across subgroups. The presumed interplay of propensity and exposure is evident for females and males. The corresponding interaction term turns out to be significant among both genders: females and males with a high propensity to shoplift are more affected by shoplifting-conducive exposure than their low-propensity counterparts. In other words, the effect of exposure to criminogenic settings on young people's shoplifting activity is stronger for those with a high crime propensity, and this finding applies to both female and male respondents ${ }^{12}$.

- Insert Table 5 about here -

Figure 1 gives the respective interaction diagrams. It can be seen that shoplifting-related exposure makes a difference when the propensity to shoplift is high, but not when the propensity is low, and that this is the case both among females and males.

- Insert Figure 1 about here -

A detailed inspection of the group-specific regression results reveals that SAT's explanatory power is slightly greater for females' shoplifting delinquency. The proportion of explained variance is $28 \%$ for female and $22 \%$ for male (logged) shoplifting frequency. This difference is too small to warrant deeper conclusions.

A comparison of the gender-specific regression models hints at slight differences in the conditional first-order slopes. To assess whether the regression weights of propensity, exposure and their interaction vary significantly across gender, a three-way interaction model was estimated (Table 6). This model includes all possible two-way interaction terms (gender*propensity, gender*exposure, propensity*exposure) and the corresponding three-way interaction term (gender*propensity*exposure). Its results show that neither the simple propensity or exposure effects nor the impact of the propensity-exposure interaction differ significantly between female and male respondents ${ }^{13}$. This observation once again backs the generalizability assumption.

- Insert Table 6 about here -

\footnotetext{
${ }^{12}$ A replication of the analyses with untransformed shoplifting frequency as dependent variable provides substantively identical results.

${ }^{13}$ Fitting the three-way interaction model with untransformed shoplifting frequency as the response variable provides substantively identical results.
} 
Sensitivity analyses

The previous analyses are based on a linear modelling approach. Linear regression maximizes the chances for detecting significant interaction effects, but entails the risk of taking floor or ceiling effects for interaction (Osgood et al., 2002). Besides, as outlined in the methodological section of this article, skewed crime frequency measures violate crucial assumptions of OLS regression models, which may result in biased standard errors and test statistics.

To assess whether the findings are robust in a non-linear framework, the linear models were re-estimated as logistic regression analyses. Binary logistic regression was selected for the sensitivity analyses, because for this technique a special procedure for examining (total) interaction effects is available - the so-called INTEFF procedure developed by Ai and Norton (2003). Remember that in non-linear models the form of the function that links the dependent variable to the linear combination of the independent variables (often the log or the logit) forces the marginal effect of each predictor variable to be conditional on the value of each predictor in the model, rendering a significant product term neither necessary nor sufficient for claiming interaction (Berry et al., 2010; Bowen, 2012). Drawing on partial derivatives, INTEFF computes specific total interaction effects for each observation in a data set, which are then averaged and equipped with standard errors. These total interaction effects combine both the model-inherent interaction that stems from the form of the employed link function and the interaction associated with the introduction of a product term.

Since Ai and Norton (2003) have implemented their procedure only for models with binary response variables, examining the robustness of the findings gained in a linear context was carried out by means of a series of logistic regression analyses. For this purpose, shoplifting frequency had to be dichotomized to a prevalence measure, with 0 indicating the absence of any acts of shoplifting in the year preceding the survey and 1 denoting the involvement in at least one act of shoplifting. Owing to the low prevalence of shoplifting in the sample $(5.1 \%)$ and the fact that only $1 \%$ of the respondents reported five or more acts of shoplifting, this categorization results in little loss of information.

Appendix 2 and 3 give the results of the logit analyses. In essence, the findings of the OLS models are replicated. Boys are more likely to be involved in shoplifting than girls. The gender effect loses its significance as soon as crime propensity and criminogenic exposure are added to the models. The INTEFF procedure provides firm evidence of interaction ${ }^{14}$ : the impact of exposure on the prevalence of shoplifting is significantly greater among individuals

\footnotetext{
${ }^{14}$ INTEFF was conducted with Stata 14 (StataCorp, 2015).
} 
of high crime propensity. And last but not least, this pattern of interaction emerges both among males and females. In all, these findings demonstrate that SAT can successfully deal with both the gender ratio and the generalizability issue regarding adolescent shoplifting delinquency.

\section{CONCLUSIONS}

One of the core findings of previous criminological inquiry is that males commit more crime than females (Steffensmeier \& Allan, 1996). Knowledge about the causes of this gender gap has remained scarce, however. Although numerous theories have been applied to the gender difference in criminal involvement (Agnew, 2009), none has proven to be capable of entirely accounting for the male crime surplus. This is true also for the gender gradient of adolescent shoplifting, which - surprisingly in light of the prevalence of the crime - has not received much empirical attention.

The present study examines both SAT's potential to explain why males are more likely to shoplift than females and whether the key concepts of the theory relate similarly to male and female shoplifting. Regression models based on survey data from nearly 3,000 Austrian adolescents suggest that SAT can successfully deal with both the gender ratio and the generalizability issue regarding adolescent shoplifting.

Descriptive results show that males commit more acts of shoplifting than females. Entering shoplifting propensity and shoplifting-related criminogenic exposure, as well as their interaction, into regression equations reduces the gender effect by $80 \%$ and renders it insignificant. The absence of any significant gender gap after controlling for these variables supports SAT's explanation of why males are more involved in shoplifting than females.

Gender-specific analyses reveal that SAT not only helps to explain the gender effect, but is also valid for males and females. Among both male and female respondents a significant propensity-exposure interaction emerges; the effect of criminogenic exposure grows when propensity for crime increases. This interaction effect does not differ between males and females; for both genders exposure to shoplifting-conducive settings affects shoplifting frequency particularly among individuals with a high propensity to steal from shops. Male and female adolescents with a low propensity to shoplift appear to be more resistant to criminogenic influences from the environment. 
These findings also provide strong support for SAT in general. Leaving gender aside, the hypothesized interplay of crime propensity and criminogenic exposure accounts for young people's shoplifting, adding further evidence to the conclusion that SAT is a general theory of criminal conduct (Wikström, 2006).

In sum, our results provide more evidence for the differential exposure hypothesis than they corroborate the vulnerability hypothesis. The causes of shoplifting delinquency are distributed unevenly between the genders, but their relationship to shoplifting is by and large the same for males and females. Males report higher levels of criminal propensity and criminogenic exposure than females, which means they spend more time in criminogenic contexts to which they are more susceptible. It is this more frequent convergence of crime-driving personal and environmental factors among males that explains their heavier involvement in shoplifting; the impact of this particularly criminogenic propensity-exposure combination is identical for male and female adolescents.

As with all research, there are some methodological limitations of this study that must be addressed.

First of all, the cross-sectional nature of the present work implies problems for establishing causality. The outcome variable (shoplifting frequency in the year preceding the survey) dates from before the employed predictors, which is standard operating procedure for this kind of study and is discussed in detail elsewhere ${ }^{15}$ (Wikström et al. 2012, p. 129 ff.). However, there is little reason to assume that prior offending creates specific types of interaction between the utilized explanatory factors. Furthermore: the main objective of this study is to tackle the gender divide in shoplifting, and gender may certainly be regarded as a very stable characteristic that is not subject to change over time ${ }^{16}$.

Limitations also result from our measurement of SAT's central concepts. The fact that our measure of shoplifting-related morality combines cognitive beliefs with the emotions of guilt and shame is certainly a strength, at least compared to other tests of SAT which often draw solely on moral beliefs (e.g. Haar \& Wikström, 2010; Svensson \& Pauwels, 2010). However, our measure of the ability to exercise self-control only partially reflects the concept as defined in SAT. The employed attitudinal self-control measure is strongly influenced by the Grasmick et al. (1993b) scale, which was developed to capture self-control in the sense of Gottfredson

\footnotetext{
${ }^{15}$ Using lag periods of one to two years between measures of propensity and exposure and acts of crime, which is the norm in longitudinal criminological research, is equally problematic given the perception-choice process being tested occurs over a matter of seconds, not years.

${ }^{16}$ We are well aware that in singular cases the gender identity of an individual may change over the life-course.
} 
and Hirschi (1990) and at best depicts the ability to withstand current temptations and provocations. Certainly it is not an exact operationalization of the capability of resisting situational incentives or external pressures to act against one's own personal morals (Wikström \& Treiber, 2016). Future research testing SAT without doubt needs measures of self-control that are more in line with the definition of the concept within the theory.

Another weakness is our incomplete measure of exposure to shoplifting-conducive settings. Although potent enough to account for the gendered nature of adolescent shoplifting activity, it nevertheless fails to fully capture the level of shoplifting-related criminogenic exposure. The amount of time spent in shops or the presence (or absence) of people other than peers are not included in our operationalization. This deficiency may lead us to underestimate the explanatory contribution of shoplifting-relevant exposure. On the other hand: it is well known that, due to projection bias and false consensus effects, indirect measures of peer delinquency tend to overestimate the influence of delinquent friends on respondents' behavior (Rebellon \& Modecki, 2013).

Besides, association with delinquent peers is a justifiable, but somewhat atypical measure of the moral context and therewith exposure to criminogenic settings. Other studies testing SAT have relied on lifestyle risk (e.g. Svensson \& Pauwels, 2010; Wikström \& Butterworth, 2006) or time spent in settings with low collective efficacy (e.g. Wikström et al., 2010, 2012) as a measure of criminogenic exposure. The employed scales of lifestyle risk usually include involvement with delinquent friends as one empirical indicator among others. Nevertheless: neither does our measure of exposure capture the amount of time respondents spend together with crime-prone peers in specific shops nor does it provide a really situational analysis of setting criminogeneity and the commitment of acts of shoplifting. Beyond all doubt, the space-time budget (Wikström et al., 2012) represents a more promising approach to tapping into the situational nature of criminal activity. The space-time budget provides a detailed hour-by-hour measure of criminogenic exposure that allows to overcome the deficiencies of generalized survey measures of exposure to high-risk environments. Measuring exposure and action at the same point in time is key to adequately testing SAT.

It is also true that our measure of deterrence is not located at the situational level. Decontextualized generalized perceptions of detection risk may more capture the respondents' overall sensitivity to risk than they depict their exposure to settings with varying deterrent capacities (Wikström, 2008). Generalized risk perceptions do not allow to relate the deterrent quality of a specific setting to the behavioral response. Hence it remains open to what extent 
deterrence perceptions are shaped by exposure to certain settings and whether an individual refrains from offending due to the deterrent character of a given setting. These are issues that should be addressed in future inquiries on SAT.

And, of course, owing to experiential (Saltzman et al., 1982) and selection effects (Matsueda $\&$ Anderson, 1998) the cross-sectional nature of our study and with this the temporal ordering of the concepts becomes especially problematic in the case of peer delinquency and perceived sanction risk.

Finally, it remains unclear to what extent our findings generalize to other crimes. Juvenile shoplifting differs from other offenses in the sense that it is an instrumental crime that is often committed in groups, normally causes little damage, and satisfies common adolescent goals (Klemke, 1992) ${ }^{17}$. Whether our results are also valid for more serious types of crime is a question for future research.

Overall, our findings support the assertions of SAT that gender is related to crime propensity and criminogenic exposure and their intersection, and that these factors can explain male and female offending equally well, while at the same time accounting for the skewed gender ratio in crime involvement. The next question we must ask is "Why are there gender differences in crime propensity and criminogenic exposure?". The complex causal chain between gender and crime propensity or criminogenic exposure marks a worthwile field for future research. In this paper we have tested SAT's situational model, but the theory has been enriched with developmental and social models to explain the emergence of people and settings and the processes of selection which bring them together (Wikström, 2005; Wikström \& Treiber, 2016). Exploring these processes in relation to gender may provide further insights into existing differences in and the (causes of the) causes of male and female patterns of crime involvement. Svensson and colleagues' (2016) initial test of gendered socialization processes may represent a good starting point.

In a broader sense, the reported findings suggest that integrative theories comprising both personal and environmental factors (and especially their interaction) are more effective in explaining the gender ratio of criminal behavior than traditional one-sided theories. The major criminological perspectives which often emphasize either person- or environment-oriented influcencing factors often fail to fully account for the relationship between gender and offending (Agnew, 2009). Usually they can explain parts but not all of the gender gap in

\footnotetext{
${ }^{17}$ Studies on the motivation underlying juvenile shoplifting have found three main driving factors: financial reasons, excitement, and group-related motives (Farrington, 1999; Klemke, 1992). Obtaining thrill and impressing friends through shoplifting activity may be regarded as instrumental motives among adolescents.
} 
juvenile delinquency (Weerman et al., 2015). Hence, for obvious reasons, it will make sense to examine how successful other theories focusing on person-environment interactions - such as Wright et al.'s (2001) life-course model of interdependence or Hay and Meldrum's (2016) life-course self-control theory - can address the gendered nature of adolescent shoplifting or juvenile delinquency in general. 


\section{Acknowledgements}

The authors express their thanks to Per-Olof Wikström of Cambridge University for his support in developing the questionnaire. We also thank various anonymous reviewers for their constructive and detailed comments.

\section{Funding}

The research underlying this article was funded under grant no. SPA03-56 by the Sparkling Science Research Program of the Austrian Federal Ministry of Science and Research.

\section{Declaration of Conflicting Interests}

The authors declare no potential conflict of interest with respect to the research, authorship and publication of this article. 


\section{REFERENCES}

Ai, C., \& Norton, E. (2003). Interaction terms in logit and probit models. Economic Letters, $80,123-129$.

Agnew, R. (2009). The contribution of "mainstream" theories to the explanation of female delinquency. In M. Zahn (Ed.), The delinquent female (pp. 7-29). Philadelphia: Temple University Press.

Aiken, L., \& West, S. (1991). Multiple regression: Testing and interpreting interactions. London: Sage.

Alarid, L., Burton, V., \& Cullen, F. (2000). Gender and crime among felony offenders: Assessing the generality of social control and differential association theories. Journal of Research in Crime and Delinquency, 37, 171-199.

Arneklev, B., Grasmick, H., Tittle, C., \& Bursik, R. (1993). Low self-control and imprudent behavior. Journal of Quantitative Criminology, 9, 225-239.

Bamfield, J. (2012). Shopping and crime. New York: Palgrave.

Belsky, J., \& Pluess, M. (2009). Beyond diathesis stress: Differential susceptibility to environmental influences. Psychological Bulletin, 135, 885-908.

Berry, W., DeMeritt, J., \& Esarey, J. (2010). Testing for interaction in binary logit and probit models: Is a product term essential? American Journal of Political Science, 54, 248-266.

Blakemore, S., \& Choudhury, S. (2006). Development of the adolescent brain: Implications for executive function and social cognition. Journal of Child Psychology and Psychiatry, 47, 296-312.

Blanco, C., Grant, J., Petry, N., Simpson, H., Alegria, A., Liu, S., \& Hasin, D. (2008). Prevalence and correlates of shoplifting in the United States: Results from the National Epidemiologic Survey on Alcohol and Related Conditions (NESARC). American Journal of Psychiatry, 165, 905-913.

Bottcher, J. (2001). Social practices of gender: How gender relates to delinquency in the everyday lives of high-risk youth. Criminology, 39, 893-932.

Bowen, H. (2012). Testing moderating hypotheses in limited dependent variable and other nonlinear models: Secondary versus total interactions. Journal of Management, 38, 860 889.

Broidy, L. \& Agnew, R. (1997). Gender and crime: A general strain theory perspective. Journal of Research in Crime and Delinquency, 34, 275-306.

Bundeskriminalamt (2012). Polizeiliche Kriminalstatistik. Bundesrepublik Deutschland. Berichtsjahr 2011. Wiesbaden: Bundeskriminalamt.

Bunge, M. (2004). How does it work? The search for explanatory mechanisms. Philosophy of the Social Sciences, 34, 182-210.

Burton, V., Cullen, F., Evans, T., Alarid, L., \& Dunaway, R. (1998). Gender, self-control, and crime. Journal of Research in Crime and Delinquency, 35, 123-147. 
Centre for Retail Research (2011). The Global Retail Theft Barometer 2010. Monitoring the costs of shrinkage and crime in the global retail industry. The worldwide shrinkage survey. Newark: CRR.

Daly, K., \& Chesney-Lind, M. (1988). Feminism and criminology. Justice Quarterly, 5, 497535.

Ellis, L., Beaver, K., \& Wright, J. (2009). Handbook of crime correlates. Oxford: Elsevier.

Enzmann, D. (2010). Germany. In J. Junger-Tas et al. (Eds.), Juvenile Delinquency in Europe and beyond. Results of the Second International Self-Report Delinquency Study (pp. 4764). New York: Springer.

Farrington, D. (1999). Measuring, explaining and preventing shoplifting: A review of British research. Security Journal, 12, 9-27.

Ferguson-Smith, A. C. (2011). Genomic imprinting: The emergence of an epigenetic paradigm. Nature Reviews Genetics, 12, 565-575.

Gangl, M. (2010). Causal inference in sociological research. Annual Review of Sociology, 36, 21-47.

Gavray, C., Vettenburg, N., Pauwels, L., \& Brondeel, R. (2013). The impact of societal vulnerability and violent values on self-control in a Belgian sample of youth: A gender comparison. Journal of Contemporary Criminal Justice, 29, 113-131.

Gottfredson, M., \& Hirschi, T. (1990). A general theory of crime. Stanford: Stranford University Press.

Grasmick, H., Blackwell, B., \& Bursik, R. (1993a). Changes in the sex patterning of perceived threats of sanctions. Law \& Society Review, 27, 679-705.

Grasmick, H., Tittle, C., Bursick, R., \& Arneklev, B. (1993b). Testing the core empirical implications of Gottfredson and Hirschi's General Theory of Crime. Journal of Research in Crime and Delinquency, 30, 5-29.

Haar, D., \& Wikström, P.-O. (2010). Crime propensity, criminogenic exposure and violent scenario responses: Testing situational action theory in regression and Rasch models. European Journal of Applied Mathematics, 21, 307-323.

Hagan, J. (1989). Structural criminology. New Brunswick: Rudgers University Press.

Hannon, L., \& Knapp, P. (2003). Reassessing nonlinearity in the urban disadvantage / violent crime relationship: An example of methodological bias from log-transformation. Criminology, 41, 1427-1448.

Hay, C., \& Meldrum, R. (2016). Self-control and crime over the life course. London: Sage.

Hayslett-McCall, K., \& Bernard, T. (2002). Attachment, masculinity, and self-control: A theory of male crime rates. Theoretical Criminology, 6, 5-33.

Hilbe, J. (2011). Negative binomial regression. Cambridge: Cambridge University Press.

Hindelang, M., Hirschi, T., \& Weiss, J. (1981). Measuring delinquency. London: Sage.

Hirtenlehner, H., \&Blackwell, B. (2015). Can differences in attachment to parents and level of self-control explain the gender gap in juvenile delinquency? Testing a gendered attachment-self-control theory. In J. Guzman (Ed.), Advances in criminology research (pp. 91-116). New York: Nova. 
Hirtenlehner, H., Blackwell, B., Leitgöb, H., \& Bacher, J. (2014). Explaining the gender gap in juvenile shoplifting. A power-control theoretical analysis. Deviant Behavior, 35, 4165.

Hubbard, D., \& Pratt, T. (2002). A meta-analysis of the predictors of delinquency among females. Journal of Offender Rehabilitation, 34, 1-13.

Jessor, R. (1992). Risk behavior in adolescence: A psychosocial framework for understanding and action. Developmental Review, 12, 374-390.

Junger-Tas, J., Ribeaud, D., \& Cruyff, M. (2004). Juvenile delinquency and gender. European Journal of Criminology, 1, 333-375.

Karaca-Mandic, P., Norton, E., \& Dowd, P. (2012). Interaction terms in non-linear models. Health Services Research, 47, 255-274.

Killias, M., Aebi, F., Herrmann, L., Dilitz, C., \& Lucia, S. (2010). Switzerland. In J. JungerTas. et al. (Eds.), Juvenile Delinquency in Europe and beyond. Results of the Second International Self-Report Delinquency Study (pp. 79-95). New York: Springer.

Klemke, L. (1992). The sociology of shoplifting: Boosters and snitches today. Westport: Praeger.

Krasnovsky, T., \& Lane, R.C. (1998). Shoplifting: A review of the literature. Aggression and Violent Behavior, 3, 219-236.

LaGrange, T., \& Silverman, R. (1999). Low self-control and opportunity: Testing the General Theory of Crime as an explanation for gender differences in delinquency. Criminology, $37,41-72$.

Lipina, S., \& Posner, M. (2012). The impact of poverty on the development of brain networks. Frontiers in Human Neuroscience, 6, article 238.

Marshall, I.H., \& Enzmann, D. (2012). The generalizability of Self-Control Theory. In J. Junger-Tas et al. (Eds.), The many faces of youth crime. Contrasting theoretical perspectives on juvenile delinquency across countries and cultures (pp. 285-325). New York: Springer.

Marshall, C. (2013). Self-reported property crime patterns in 30 countries: Adventures in multivariate exploratory data analysis. Journal of Contemporary Criminal Justice, 29, $125-146$.

Matsueda, R., \& Anderson, K. (1998). The dynamics of delinquent peers and delinquent behavior. Criminology, 36, 269-306.

McClelland, G., \& Judd, C. (1993). Statistical difficulties of detecting interactions and moderation effects. Psychological Bulletin, 114, 376-390.

Mears, D., Ploeger, M., \& Warr, M. (1998). Explaining the gender gap in delinquency: Peer influence and moral evaluations of behavior. Journal of Research in Crime and Delinquency, 35, 251-266.

Messerschmidt, J. (1993). Masculinities and crime. Critique and reconceptualization of theory. Lanham: Rowman \& Littlefield.

Moffitt, T., Caspi, A., Rutter, M., \& Silva, P. (2001). Sex differences in antisocial behavior. Conduct, disorder, delinquency, and violence in the Dunedin longitudinal study. Cambridge: Cambridge University Press. 
Osgood, W., Finken, L., \& McMorris, B. (2002). Analyzing multiple-item measures of crime and deviance II: Tobit regression analysis of transformed scores. Journal of Quantitative Criminology, 18, 319-347.

Paternoster, R., Brame, R., Mazerolle, P., \& Piquero, A. (1998). Using the correct statistical test for the equality of regression coefficients. Criminology, 36, 859-866.

Pauwels, L. (2012). How similar is the interaction between low self-control and deviant moral beliefs in the explanation of adolescent offending? An inquiry in subgroups by gender and immigrant background. In A. Fruili \& L. Veneto (Eds.), Psychology of morality (pp. 141153). New York: Nova.

Pauwels, L. (2015). Über die Haltbarkeit der in der Situational Action Theory beschriebenen Interaktionseffekte in verschiedenen Bevölkerungsgruppen. Monatsschrift für Kriminologie und Strafrechtsreform, 98, 280 - 296.

Piquero, N.L., Gover, A., MacDonald, J., \& Piquero, A. (2005). The influence of delinquent peers on delinquency: Does gender matter? Youth \& Society, 36, 251-275.

Piquero, N., \& Sealock, M. (2004). Gender and general strain theory: A preliminary test of Broidy and Agnew's gender/GST hypotheses. Justice Quarterly, 21, 125-158.

Rebellon, C., \& Modecki, K. (2013). Accounting for projection bias in models of delinquent peer influence: The utility and limits of latent variable approaches. Journal of Quantitative Criminology, 30, 163-186.

Russell, C., \& Dean, M. (2000). To log or not to log: Bootstrap as an alternative to the parametric estimation of moderation effects in the presence of skewed dependent variables. Organizational Research Methods, 3, 166-185.

Rutter, M. (2012). Gene-environment interdependence. European Journal of Developmental Psychology, 9, 391-412.

Saltzman, L., Paternoster, R., Waldo, G., \& Chiricos, T. (1982). Deterrent and Experiential Effects: The Problem of Causal Order in Perceptual Deterrence Research. Journal of Research in Crime and Delinquency, 19, 172-189.

Schils, N., \& Pauwels, L. (2014). Explaining violent extremism for subgroups by gender and immigrant background: Using SAT as a framework. Journal of Strategic Security, 7, 2747.

Simons, R., Burt, C., Barr, A., Lei, M., \& Stewart, E. (2014). Incorporating routine activities, activity spaces, and situational definitions into the social schematic theory of crime. Criminology, 52, 655-687.

The Smart Cube: Checkpoint Systems (2015). Global Retail Theft Barometer 2014-2015. http://www.globalretailtheftbarometer.com/

Treiber, K. (in press). Biosocial criminology and models of criminal decision making. In W. Bernasco, J.L. van Gelder \& H. Elffers (Eds.), The Oxford handbook of offender decision making. Oxford: Oxford University Press.

StataCorp (2015). Stata Statistical Software: Release 14. College Station: StataCorp.

Steffensmeier, D., \& Allan, E. (1996). Gender and crime: Toward a gendered theory of female offending. Annual Review of Sociology, 22, 459-487.

Steketee, M., Junger, M., \& Junger-Tas, J. (2013). Sex differences in the predictors of juvenile delinquency females are more susceptible to poor environments; males are 
influenced more by low self-control. Journal of Contemporary Criminal Justice, 29, 88105.

Stummvoll, G., Kromer, I., \& Hager, I. (2010). Austria. In J. Junger-Tas et al. (Eds.) Juvenile delinquency in Europe and beyond. Results of the Second International Self-Report Delinquency Study (pp. 97-110). New York: Springer.

Svensson, R. (2004). Shame as a consequence of the parent-child relationship: A study of gender differences in juvenile delinquency. European Journal of Criminology, 1, 477504.

Svensson, R., \& Pauwels, L. (2010). Is a risky lifestyle always "risky"? The interaction between individual propensity and lifestyle risk in adolescent offending: A test in two urban samples. Crime \& Delinquency, 56, 608-626.

Svensson, R., Pauwels, L., Weerman, F., \& Bruinsma, G. (2016). Explaining individual changes in moral values and moral emotions among adolescent boys and girls: A fixedeffects analysis. European Journal of Criminology, DOI: 10.1177/1477370816649626.

Thijs, P., van Dijk, I., Stoof, R., \& Notten, N. (2015). Adolescent problem behaviour: The gender gap in European perspective. European Journal of Criminology, 12, 598-615.

Tonglet, M. (2002). Consumer misbehaviour: An exploratory study of shoplifting. Journal of Consumer Behaviour, 1, 336-354.

Vazsonyi, A., Pickering, E., Junger, M., \& Hessing, T. (2001). An empirical test of a General Theory of Crime: A four-nation comparative study of self-control and the prediction of deviance. Journal of Research in Crime and Delinquency, 38, 91-131.

Warr, M. (2002). Companions in crime. The social aspects of criminal conduct. Cambridge: Cambridge University Press.

Weerman, F., Bernasco, W., Bruinsma, G., \& Pauwels, L. (2015). Gender differences in delinquency and Situational Action Theory: A partial test. Justice Quarterly, DOI: 10.1080/07418825.2015.1064987.

Weerman, F., \& Hoeve, M. (2012). Peers and delinquency among females and males: Are sex differences in delinquency explained by peer factors? European Journal of Criminology, 9, 228-244.

Wikström, P.-O. (2004). Crime as alternative. Towards a cross-level Situational Action Theory of crime causation. In J. McCord (Ed.), Beyond empiricism: Institutions and intentions in the study of crime (pp. 1-37). New Brunswick: Transaction.

Wikström, P.-O. (2005). The social origins of pathways in crime: Towards a developmental ecological action theory of crime involvement and its changes. In D. Farrington (Ed.), Integrated developmental and life-course theories of offending. Advances in criminological theory. Volume 14 (pp. 211-245). New Brunswick: Transaction.

Wikström, P.-O. (2006). Individuals, settings and acts of crime. Situational mechanisms and the explanation of crime. In P.-O. Wikström \& R. Sampson (Eds.), The explanation of crime: Context, mechanisms and development (pp. 61-107). Cambridge: Cambridge University Press.

Wikström, P.-O. (2007). In search of causes and explanations of crime. In R. King \& E. Wincup (Eds.), Doing research on crime and justice (pp. 117-140). Oxford: Oxford University Press. 
Wikström, P.-O. (2008). Deterrence and deterrence experiences: Preventing crime through the threat of punishment. In S. Shoham, O. Beck \& M. Kett (Eds.), International handbook of penology and criminal justice (pp. 345-378). Boca Raton: CRC Press.

Wikström, P.-O. (2010). Explaining crime as moral action. In S. Hitlin \& S. Vaisey (Eds.), Handbook of the sociology of morality (pp. 211-240). New York: Springer.

Wikström, P.-O. (2012). Does everything matter? Addressing the problem of causation and explanation in the study of crime. In J. McGloin, C. Sullivan \& L. Kennedy (Eds.), When crime appears. The role of emergence (pp. 53-72). New York: Routledge.

Wikström, P.-O. (2014). Why crime happens: A Situational Action Theory. In G. Manzo (Ed.), Analytical sociology: Actions and networks (pp. 74-94). Chicester: Wiley \& Sons.

Wikström, P.-O., \& Butterworth, D. (2006). Adolescent crime. Individual differences and lifestyles. New York: Routledge.

Wikström, P-O., Ceccato, V., Hardie, B., \& Treiber, K. (2010). Activity fields and the dynamics of crime. Advancing knowledge about the role of the environment in crime causation. Journal of Quantitative Criminology, 26, 55-87.

Wikström, P.-O., Oberwittler, D., Treiber, K., \& Hardie, B. (2012). Breaking rules. The social and situational dynamics of young people's urban crime. Oxford: Oxford University Press.

Wikström, P.-O., \& Treiber, K. (2016). Situational theory: The importance of interactions and action mechanisms in the explanation of crime. In A. Piquero (Ed.), The handbook of criminological theory (pp. 415-444). Chichester: Wiley \& Sons.

Wittenberg, J. (2009). Diebstahlskriminalität von Jugendlichen. Eine Überprüfung der Theorie des geplanten Verhaltens am Beispiel des Ladendiebstahls. Münster: Waxmann.

Wong, T., Slotboom, A., \& Bijleveld, C. (2010). Risk factors for delinquency in adolescent and young adult females: A European Review. European Journal of Criminology, 7, 266284.

Wright, B., Caspi, A., Moffitt, T., \& Silva, P. (2001). The effects of social ties on crime vary by criminal propensity: A life-course model of interdependence. Criminology, 39, 321351. 
Figure 1: Interaction diagram

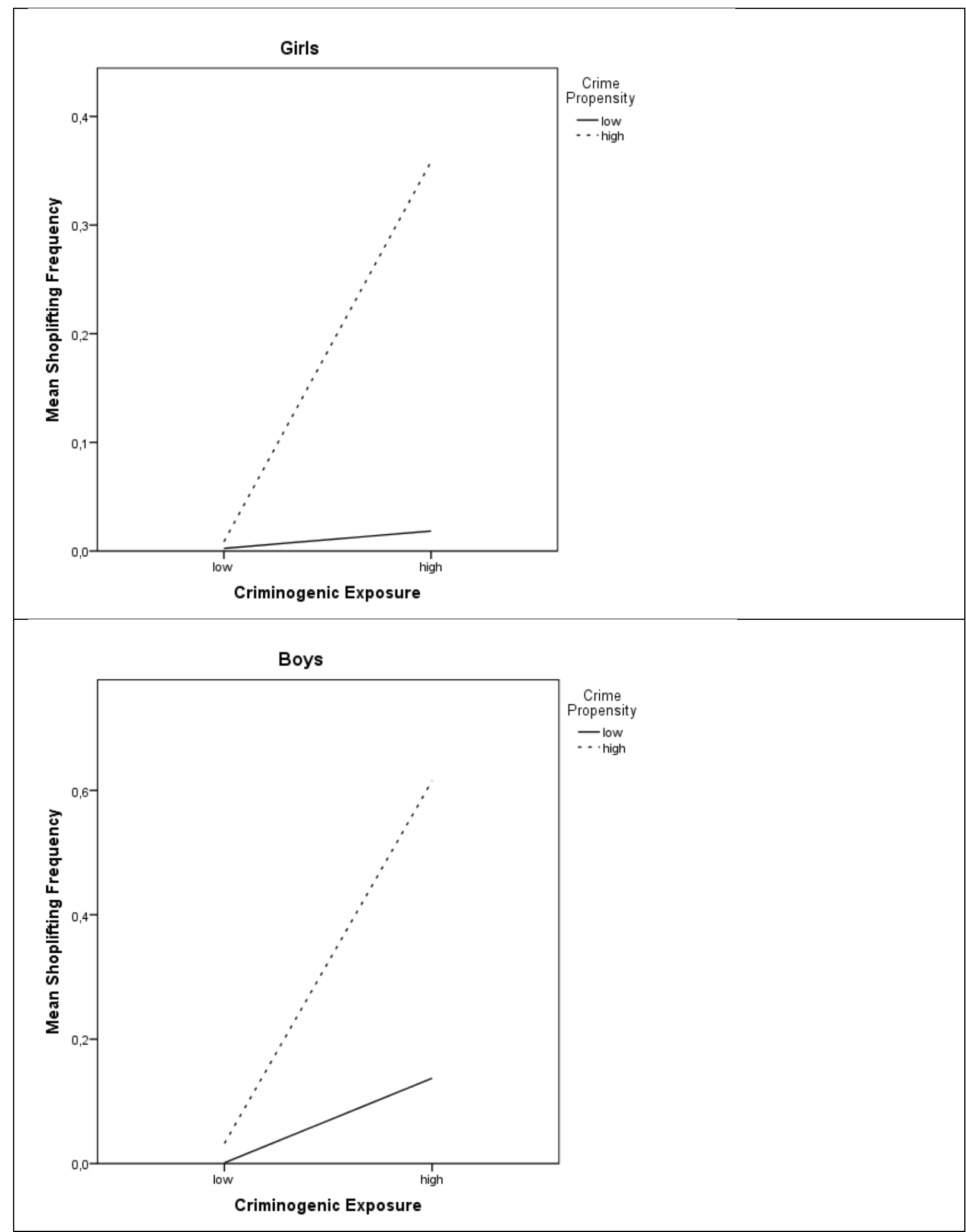

Note: propensity and exposure are dichotomized at the median. 
Table 1: Sample composition $(\mathrm{n}=2,911)$

\begin{tabular}{lcc} 
Characteristic & $\begin{array}{c}\text { Unweighted } \\
\text { data }\end{array}$ & $\begin{array}{c}\text { Weighted } \\
\text { data }\end{array}$ \\
\hline Sex & $52 \%$ & $50 \%$ \\
Males & $48 \%$ & $50 \%$ \\
Females & & \\
Age & $19 \%$ & $21 \%$ \\
12 years & $43 \%$ & $43 \%$ \\
13 years & $32 \%$ & $30 \%$ \\
14 years & $6 \%$ & $6 \%$ \\
15 or more years & & \\
Grade & $50 \%$ & $50 \%$ \\
$7^{\text {th }}$ class & $50 \%$ & $50 \%$ \\
$8^{\text {th }}$ class & & \\
Province & $58 \%$ & $49 \%$ \\
Upper Austria & $42 \%$ & $51 \%$ \\
Lower Austria & &
\end{tabular}

Table 3: Gender differences

\begin{tabular}{lccc} 
Variable & Males & Females & $\mathrm{p}(\alpha$-error) \\
\hline 1-year prevalence of shoplifting & $7.3 \%$ & $2.8 \%$ & .000 \\
1-year frequency of shoplifting $(\varnothing)$ & +0.29 & +0.09 & .001 \\
Propensity (Z-score) $(\varnothing)$ & +0.14 & -0.19 & .000 \\
Exposure (Z-score) $(\varnothing)$ & +0.21 & -0.23 & .000 \\
High propensity AND high exposure & $42.2 \%$ & $22.9 \%$ & .000
\end{tabular}


Table 2: Correlation matrix (product-moment correlation coefficients)

\begin{tabular}{|l|c|c|c|c|}
\hline & 1. & 2. & 3. & 4. \\
\hline 1. Shoplifting frequency & $1.00(.88)$ & & & \\
2. Propensity & $.24^{* * *(.32)}$ & 1.00 & & \\
3. Exposure & $.28^{* * *}(.32)$ & $.53^{* * *}$ & 1.00 & \\
4. Gender (male) & $.07 * *(.09)$ & $.17^{* * *}$ & $.22^{* * *}$ & 1.00 \\
\hline Arithmetic mean / Standard deviation & $0.19 / 1.43$ & $-0.04 / 1.64$ & $-0.02 / 1.63$ & $0.50 / 0.50$ \\
\hline
\end{tabular}

$* \mathrm{p} \leq .05 ; * * \mathrm{p} \leq .01 ; * * * \mathrm{p} \leq .001 \quad()$ : correlation with logged shoplifting frequency

Table 4: Predictors of log-transformed shoplifting frequency

(linear regression analyses with clustered robust standard errors)

\begin{tabular}{|c|c|c|c|c|c|c|}
\hline & \multicolumn{2}{|c|}{ Model 1} & \multicolumn{2}{|c|}{ Model 2} & \multicolumn{2}{|c|}{ Model 3} \\
\hline & B & $\mathrm{T}$ & B & $\mathrm{T}$ & $\mathrm{B}$ & $\mathrm{T}$ \\
\hline Gender (male) & $0.06 * * *$ & 4.22 & 0.01 & 0.50 & 0.01 & 1.14 \\
\hline Propensity & & & $0.05^{* * *}$ & 3.44 & $0.03 *$ & 2.35 \\
\hline Exposure & & & $0.08 * * *$ & 4.89 & $0.06 * * *$ & 3.55 \\
\hline Propensity * Exposure & & & & & $0.08 * * *$ & 4.73 \\
\hline Determination coefficient $\mathrm{R}^{2}$ & \multicolumn{2}{|c|}{$.009 * * *$} & \multicolumn{2}{|c|}{$.140 * * *$} & \multicolumn{2}{|c|}{$.236 * * *$} \\
\hline
\end{tabular}

Note: the predictors Propensity and Exposure are Z-standardized; the interaction term represents the product of the standardized predictors.

$* \mathrm{p} \leq .05 ; * * \mathrm{p} \leq .01 ; * * * \mathrm{p} \leq .001 \quad \mathrm{~B}$ : unstandardized regression coefficient; $\mathrm{T}$ : T-value 
Table 5: Predictors of log-transformed shoplifting frequency differentiated by gender (linear regression analyses with clustered robust standard errors)

\begin{tabular}{|c|c|c|c|c|c|c|c|c|}
\hline & \multicolumn{4}{|c|}{ Females } & \multicolumn{4}{|c|}{ Males } \\
\hline & \multicolumn{2}{|c|}{ Model 1} & \multicolumn{2}{|c|}{ Model 2} & \multicolumn{2}{|c|}{ Model 1} & \multicolumn{2}{|c|}{ Model 2} \\
\hline & $\mathrm{B}$ & $\mathrm{T}$ & $\mathrm{B}$ & $\mathrm{T}$ & $\mathrm{B}$ & $\mathrm{T}$ & $\mathrm{B}$ & $\mathrm{T}$ \\
\hline Propensity & $0.04 * *$ & 3.03 & $0.04 * * *$ & 3.59 & $0.06^{*}$ & 2.51 & 0.02 & 1.05 \\
\hline Exposure & $0.05^{* * *}$ & 3.25 & $0.04 * * *$ & 3.81 & $0.11^{* * *}$ & 4.04 & $0.09^{* *}$ & 2.86 \\
\hline Propensity * Exposure & & & $0.09 * * *$ & 3.86 & & & $0.08 * * *$ & 3.28 \\
\hline Determination coefficient $\mathrm{R}^{2}$ & \multicolumn{2}{|c|}{$.108 * *$} & \multicolumn{2}{|c|}{$.275^{* * *}$} & \multicolumn{2}{|c|}{$.154 * * *$} & \multicolumn{2}{|c|}{$.221 * * *$} \\
\hline
\end{tabular}

Note: the predictors Propensity and Exposure are Z-standardized; the interaction term represents the product of the standardized predictors.

$* \mathrm{p} \leq .05 ; * * \mathrm{p} \leq .01 ; * * * \mathrm{p} \leq .001 \quad \mathrm{~B}$ : unstandardized regression coefficient; $\mathrm{T}$ : $\mathrm{T}$-value

Table 6: Generalizability of the predictors of log-transformed shoplifting frequency (linear regression analysis with clustered robust standard errors)

\begin{tabular}{|l|cc|}
\hline & B & $\mathrm{T}$ \\
\hline Gender (boy) & 0.02 & 1.32 \\
Propensity & $0.04 * * *$ & 3.59 \\
Exposure & $0.04 * * *$ & 3.81 \\
Propensity * Exposure & $0.09 * * *$ & 3.86 \\
Gender * Propensity & -0.02 & 1.26 \\
Gender * Exposure & 0.05 & 1.62 \\
Gender * Propensity * Exposure & -0.01 & 0.39 \\
\hline Determination coefficient $\mathrm{R}^{2}$ & \multicolumn{2}{|c|}{$.241^{* *}$} \\
\hline
\end{tabular}

Note: the predictors Propensity and Exposure are Z-standardized; gender is included as raw score.

$* \mathrm{p} \leq .05 ; * * \mathrm{p} \leq .01 ; * * * \mathrm{p} \leq .001 \quad \mathrm{~B}$ : unstandardized regression coefficient; $\mathrm{T}$ : T-value 


\section{APPENDIX}

\section{Appendix A: Measures}

\begin{tabular}{|c|c|}
\hline Shoplifting & $\begin{array}{l}\text { How many times have you taken something from a shop without paying for it in the last } 12 \\
\text { months? (__ times) }\end{array}$ \\
\hline Morality & $\begin{array}{l}\text { How wrong is it to steal a music CD from a shop? ("very wrong" }=1 \text {, "wrong" }=2 \text {, "a little } \\
\text { wrong" }=3 \text {, "not wrong at all" = 4) } \\
\text { Would you feel guilty if you stole something from a shop? ("yes, very much" =1, "yes, a } \\
\text { little" = } 2 \text {, "no, not at all" = } 3 \text { ) } \\
\text { If you were caught shoplifting and your parents found out about it, would you feel ashamed? } \\
\text { ("yes, very much" = } 1 \text {, "yes, a little" }=2 \text {, "no, not at all" = 3) }\end{array}$ \\
\hline Self-control & $\begin{array}{l}\text { I often act on the spur of the moment without stopping to think. } \\
\text { I often try to avoid things that I know will be difficult. } \\
\text { I lose my temper pretty easily. } \\
\text { When I am really angry, other people better stay away from me. } \\
\text { I often take a risk just for the fun of it. } \\
\text { Sometimes I find it exciting to do things that are dangerous. } \\
\text { ("Strongly agree" }=4 \text {, "mostly agree" }=3 \text {, "mostly disagree" }=2 \text {, "strongly disagree" =1) }\end{array}$ \\
\hline Moral context & $\begin{array}{l}\text { Most of my friends think it is okay to take something away from a shop without paying for } \\
\text { it. ("Strongly agree" }=4 \text {, "mostly agree" }=3 \text {, "mostly disagree" }=2 \text {, "strongly disagree"= } 1 \text { ) } \\
\text { How many of your friends stole something from a shop in the last } 12 \text { months? ("none" = } 1 \text {, } \\
\text { "a few" =2, "most of them" }=3 \text {, "all" = 4) }\end{array}$ \\
\hline Deterrence & $\begin{array}{l}\text { Do you think there is a great risk of getting caught if you steal a CD in a shop? ("no risk at } \\
\text { all" = 3, "a small risk" = } 2 \text {, "a great risk" = 1, "a very great risk" = } 0 \text { ) } \\
\text { Do you think you would be in great trouble if you got caught shoplifting? ("no trouble at all" } \\
=3 \text {,"a little bit of trouble" }=2 \text {, "much trouble" }=1 \text {, "very much trouble" = } 0 \text { ) }\end{array}$ \\
\hline
\end{tabular}


Appendix B: Predictors of shoplifting prevalence

(logistic regression analyses with clustered robust standard errors)

\begin{tabular}{|c|c|c|c|c|c|c|}
\hline & \multicolumn{2}{|c|}{ Model 1} & \multicolumn{2}{|c|}{ Model 2} & \multicolumn{2}{|c|}{ Model 3} \\
\hline & $\mathrm{B}$ & $\mathrm{Z}$ & B & $\mathrm{Z}$ & $\mathrm{B}$ & $\mathrm{Z}$ \\
\hline Gender (male) & $0.99 * * *$ & 4.25 & 0.34 & 1.38 & 0.31 & 1.30 \\
\hline Propensity & & & $0.72 * * *$ & 5.30 & $0.87 * * *$ & 5.88 \\
\hline Exposure & & & $1.11 * * *$ & 7.45 & $1.22 * * *$ & 6.07 \\
\hline Propensity * Exposure (inteff) & & & & & $0.02 * * *$ & 4.47 \\
\hline Pseudo $\mathrm{R}^{2}$ & \multicolumn{2}{|c|}{$.027 * * *$} & \multicolumn{2}{|c|}{$.339 * * *$} & \multicolumn{2}{|c|}{$.340 * * *$} \\
\hline
\end{tabular}

Note: the predictors Propensity and Exposure are Z-standardized; the interaction term represents the product of the standardized predictors.

$* \mathrm{p} \leq .05 ; * * \mathrm{p} \leq .01 ; * * * \mathrm{p} \leq .001 \quad \mathrm{~B}$ : unstandardized regression coefficient; Z: Z-value

Appendix C: Predictors of shoplifting prevalence differentiated by gender (logistic regression analyses with clustered robust standard errors)

\begin{tabular}{|c|c|c|c|c|c|c|c|c|}
\hline & \multicolumn{4}{|c|}{ Females } & \multicolumn{4}{|c|}{ Males } \\
\hline & \multicolumn{2}{|c|}{ Model 1} & \multicolumn{2}{|c|}{ Model 2} & \multicolumn{2}{|c|}{ Model 1} & \multicolumn{2}{|c|}{ Model 2} \\
\hline & B & $\mathrm{Z}$ & B & $\mathrm{Z}$ & B & $\mathrm{Z}$ & B & $\mathrm{Z}$ \\
\hline Propensity & $1.07 * * *$ & 5.66 & $0.92 * * *$ & 4.16 & $0.59 * * *$ & 3.84 & $0.87 * * *$ & 5.41 \\
\hline Exposure & $0.94 * * *$ & 6.79 & $0.68 * *$ & 3.17 & $1.16^{* * *}$ & 6.07 & $1.34 * * *$ & 5.71 \\
\hline Propensity $*$ Exposure (inteff) & & & $0.02 * * *$ & 3.33 & & & $0.01 * * *$ & 4.49 \\
\hline Pseudo $\mathrm{R}^{2}$ & \multicolumn{2}{|c|}{$.361 * *$} & \multicolumn{2}{|c|}{$.366^{* * * *}$} & \multicolumn{2}{|c|}{$.307 * * *$} & \multicolumn{2}{|c|}{$.312 * * *$} \\
\hline
\end{tabular}

Note: the predictors Propensity and Exposure are Z-standardized; the interaction term represents the product of the standardized predictors.

$* \mathrm{p} \leq .05 ; * * \mathrm{p} \leq .01 ; * * * \mathrm{p} \leq .001 \quad \mathrm{~B}$ : unstandardized regression coefficient; $\mathrm{Z}: \mathrm{Z}$-value 